\title{
Im Buchdschungel
}

\section{Erhard Taverna}

Dr. med., Mitglied der Redaktion

Walter Moers ist ein vielseitiger Mann. Er schrieb sich in die Bestsellerlisten mit Kinderbüchern (Käpt'n Blaubär) und satirischen Comics (Das kleine Arschloch) und erfand das groteske Reich der selbst illustrierten Zamonien-Romane. Eine Welt überbordender Anspielungen, Anagramme und Neuschöpfungen, die seine Lesergemeinde auf Trab hält. Kritiker nannten sein Werk zu Recht eine phantastische Liebeserklärung an das Lesen und die Literatur. Der Roman Die Stadt der Träumenden Bücher [1] beschreibt eine gigantische Buchhandlung, ein Paradies für Antiquare, in dem es nach muffigem Staub, Säure, Zitrone, altem Leder und Druckerschwärze riecht. In den Katakomben dieser buchverrückten Stadt gerät der Held in ein Meer verwesender Bücher voller Papiermehl und Ungeziefer. Dort verfolgt ihn ein gigantischer Bücherwurm, dessen Gebrüll die Schleusen der Hölle öffnet. Käfer, gross wie Brotlaibe, eine Spinne mit wehenden weissen Haaren, schwarzgeschuppte Tentakel aus der Tiefe, farblose Krebse, leuchtende Skorpione, Raupen und

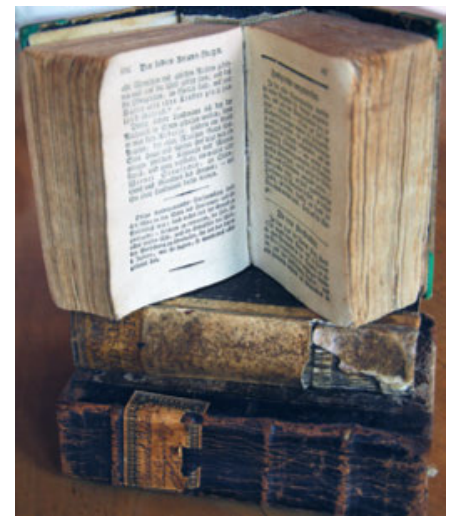

Holz, kommen auch Nagekäfer und Buchwürmer auf ihre Rechnung. Die Mischung aus Holzmehl, Kot, Sporen, Milben und Bücherstaub kann bei Archivaren zu Allergien der Haut und Atemwege führen. Nicht unbedingt so tödlich, wie Moers' lebende Bücher, die Bisswunden zufügen, kriechend, krabbelnd und flatternd, blutgierigen Ratten, Spinnen und Fledermäusen gleichen, toxisch sind oder in den Wahnsinn treiben.

Wo der Zahn der Zeit nagt, helfen Restauratoren mit einer ausgeklügelten Buchmedizin. Mit Begasungen gegen die meist unsichtbare Buchfauna, mit mehrwöchigen Badekuren für säuregeschädigtes Papier, mit Spezialleim für zerfetzte Buchecken, Kleister für gerissene Einbände und mit aufwendigen chirurgischen Massnahmen zur Heilung mechanischer Beschädigungen. Doch auch das neuste Papier synthetischer Herstellung wird einmal alt, genauso wie die elektronischen Datenträger digitalisierter Bestände. Stein und Ton sumerischer Tafeln sind als Speichermedien unübertroffen, was ihre Lebensdauer betrifft. USB-Sticks halten durchsichtige Schlangen fallen übereinander her. Ein Karneval der Untiere, der unschwer an den realen Dschungel häuslicher Bibliotheken erinnert.

Aus alten Folianten und Dokumenten riecht es nach flüchtigen organischen Verbindungen, entstanden aus dem Zerfall von Zellulose und Lignin. Stockfleckig, süsslich und floral, nach Vanillin und Mandeln. Tintenfrass und Säure, Licht und Feuchtigkeit sorgen für ein üppiges Mikrobiotop. Silberfischchen, die lichtscheuen Hausbewohner, schätzen den stärkehaltigen Klebstoff oder löschen Buchstaben und ganze Textabschnitte. Wächst ein Pilzrasen heran, wird dieser von Milben und Bücherläusen abgeweidet. Das Raubtier der Bücherwelt, der König der Nahrungskette, ist der Buchskorpion. Wenige Millimeter gross, ohne Schwanz und Stachel, spritzt er sein Gift mit den Scheren in seine Beute. Er beisst ein Loch in die Schale, pumpt Verdauungssaft hinein und saugt das Tier aus. Schon Aristoteles hat das Spinnentier mit seinen acht Beinen beschrieben. Landet eine Fliege auf dem Buchregal, klammert er sich an ein Fliegenbein und sucht sich ein neues Jagdgebiet. Sind die Buchdeckel aus dreissig Jahre, Cloud-Speicher theoretisch unbegrenzt. Eine vergoldete Scheibe aus Kupfer, die Millionen Jahre überdauern soll, hat inzwischen, als Botschaft der Erdlinge an lesefreudige Aliens, den äussersten Rand unseres Sonnensystems überschritten. Ein weiteres Beispiel von vielen ist das Rosetta-Projekt, eine Scheibe aus einer Nickellegierung mit eingeätzten Informationen, die kein digitales Format benötigen. Eine Kopie, mit der Sonde Rosetta in den Orbit befördert, liegt seit September 2016 auf dem Kometen Tschurjumow-Gerassimenko.

Die wärmeliebenden Fischchenarten der Insektenordnung Zygentoma leben seit über 300 Millionen Jahren. Sie sind keine Astronauten, aber treue Begleiter unserer erdgebundenen Spezies. Sie werden auch nach unserem Verschwinden mit weiteren Gesellen leckere Biotope finden.

Literatur

1 Moers W. Die Stadt der Träumenden Bücher. Piper Taschenbuch; 34. Auflage 2016.

Bildnachweis

Foto: Erhard Taverna 